\title{
Contact arc time - important parameter of DC high-speed circuit-breakers
}

\author{
Artur Rojek ${ }^{*}$, and Marek Skrzyniarz \\ Railway Research Institute, Chlopickiego 50, 04-275 Warsaw, Poland
}

\begin{abstract}
The parameters of DC high-speed circuit-breakers (HSCB) and test methods are specified in the standards. These standards define requirements of the circuit breakers opening time and the total breaking time. During the direct current (DC) breaking after opening the contacts, the arc ignites, the voltage of which is so low that it does not limit the switched off current. The time in which this phenomenon occurs is defined as the contact arc time.

The contact arc time has a significant influence on the breaking process. It can take up to over $40 \%$ of arcing time. Therefore, tests were carried out, which were to answer the questions about what and to a what extent affects the contact arc time.

Since the standards for high-speed circuit-breakers do not refer to the contact arc time, definitions of this parameter are proposed in the article. Using this definition numerous tests of various factors have been carried out on contact arc time.

The conducted research shows that shortening the DC breaking time through high-speed breakers is possible by limiting the contact arc time, which can be obtained by modifying the circuit breaker's construction.
\end{abstract}

\section{Introduction}

High-speed circuit-breakers (HSCB) sorted in traction substations are subject to several requirements regarding their electrical and mechanical parameters as well as their durability and reliability. The malfunctioning of the circuit-breakers may cause railway infrastructure damage or failure, rail traffic disruptions and in extreme cases may even endanger human health or life.

Breaking time is one of basic HSCR parameters particularly affecting the protection of human life and health in case of short-circuits to the available elements.

Prior to HSCR placing in service, they are subject to numerous trials and laboratory tests. The basic reference documents relating to HSCR dedicated to working in traction substations and section cabins are EN 50123-1 [3] and EN 50123-2 [4] standards as well as EN 60077-3 [7] standard defining the requirements and tests for rolling stock breakers. The provisions of latter should be read together with EN 60077-1 [5] and EN 60077-2 [6].

Many publications have been devoted to issues connected with HSCR and short-circuit breaking, including $[1,2,8,9,13,14]$, and their tests $[10,12]$. Only some of them deal with the breaking time problem and the correlation between that time and breaker's parameters, as well as circuit's parameters in which the breaker is working. The tests have shown that the parameters of the circuit and the breaking current have little influence on the contact arc time. The technical condition of the circuit breaker resulting from the number of breakings has an effect on the contact arc time, but much less than on the arcing time. The construction of the circuit breaker has the greatest influence on the tested parameter. In the case of some types of high-speed breakers, the value of the contact arc time causes that the breaking time and the limited shortcircuit current have high values despite the minimum values of the circuit breaker's opening time. Tests were carried out on the contact arc time of such factors as the high-speed circuit-breakers' construction, the time constant of the circuit, the rate of rise of the breaking current and the expected peak value of the current. Tests have also been carried out examining the impact of the number of operating current breakings made by the circuit breaker on the contact arc time. Detailed results of these tests are presented below.

\section{HSCR breaking time}

EN 50123-2 [4] and EN 60077-3 [7] standards define breaking time $t_{b}$ as the time from the moment when the current exceeds the trip setting level until the breaking current stops flowing. The breaking time $t_{b}{ }^{l}$ is the sum of opening time $t_{i}$ and arcing time $t_{a}$. The opening time $t_{i}$ is defined as the time that passes from the time when the current exceeds the trip setting level until the contacts are opened by the circuit breaker. In turn, the arcing time $t_{a}$ is the time counted from the moment the contacts are open until the current is turned off completely.

The opening time $t_{i}$ depends largely on HSCB construction - the way it is tripped and the mechanism opening the contacts $[12,13,15]$. The arcing time $t_{a}$ also depends on HSCB construction. Its duration is influenced by the construction of contacts, arc chute

\footnotetext{
${ }^{1}$ Symbols for parameters in compliance with EN 50123-1 [3]
}

*Corresponding author: arojek@ikolej.pl 
parameters, the method of arc extinguishing and the method of magnetic blowout.

Due to breaking time and the capability to limit the current, EN 50123-1 [3] and EN 50123-2 [4] standards divide high-speed breakers designed for stationary equipment into 3 types, i.e. $\mathrm{H}, \mathrm{V}$ and $\mathrm{S}$. In accordance with provisions of the standard. HSCB of $\mathrm{H}$ type is supposed to prevent reaching the peak value by the short-circuit current, have opening time $t_{i}$ not bigger than $5 \mathrm{~ms}$, whereas the total break time $t_{b}$ should not exceed $20 \mathrm{~ms}$, when the value of sustained current is at least 7 times bigger than the trigger setting level and the initial steepness of the current rise has a minimum value of $5 \mathrm{kA} / \mathrm{ms}$.

During arcing time $t_{a}$, the electric arc does not develop uniformly nor arc voltage $u_{a}$ grows linearly. After the circuit breaker's contacts open, the arc is ignited between them. This arc is short and large in diameter which means that its voltage is low. This arc moves to the arc chute where it increases its diameter and the deionization takes place. From the time of the contacts opening to moment of the arc entering the arc chamber, the arc voltage is low and practically it does not cause any limitation of the short-circuit current. The author of the publication [14] defined the period of the low voltage arc appearance as the contact arc time $t_{s}$. EN 50123-1 [3], EN 50123-2 [4] and EN 60077-3 [7] standards neither characterize nor include this parameter, although it is an important factor affecting the speed of switching off the current and the degree of its limitation.

The duration of the contact arc time $t_{s}$ and opening time $t_{i}$ essentially affect the coordination of short-circuit protection in the traction vehicle - traction substation system [11].

For the purpose of testing and analyzing their results presented in the following sections, the contact arc time $t_{s}$ is defined as the time from the moment of breaker's contacts opening (arc ignition between contacts) until the arc reaches voltage of $u_{a}=0.1 U_{d}$ (supply voltage of the circuit). Since in many cases the arc voltage $u_{a}$ varies when the current is switched off, it rises and falls, the condition $u_{a}=0.1 U_{d}$ is deemed to be fulfilled if then there is no decrease of the voltage value below $0.1 U_{d}$. The above definition of the contact arc time $t_{s}$ is graphically presented in Fig.1.

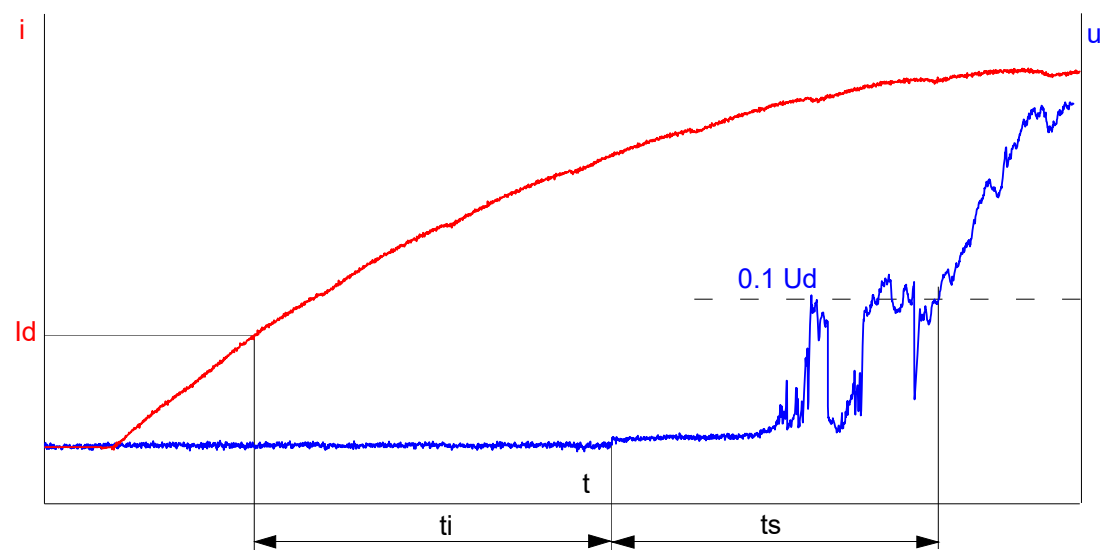

Fig. 1. Definition of contact arc time $t_{s}$.

\section{Research of contact arc time}

\subsection{High-speed breaker's construction vs. contact arc time}

Figures $2-4$ present short-circuit current and voltage flows on three types of HSCB. All the flows were recorded during tests in the same short-circuit circuit and the tested breakers has identical setting levels. The breakers differed un main and arcing contacts construction, arc chute construction and magnetic blowout systems.

The analysis of flows presented in Figures $2-4$ show that the current is still rising in the $t_{s}$ time. Type 2 breaker, for which the flows are presented in Fig. 3, despite its shortest opening time is characterized by the longest $t_{s}$ time. The consequence of this is the longest break time and the highest value of the limited (cut off) current. The breaker has a gap between the main and arcing contacts, the largest geometric dimensions of the arcing cones, and its arc chute does not contain conductive elements. This causes that the time required for the arc movement from the main contacts to the inside of the arc chute is the longest.

Paradoxically, the type 1 circuit breaker with the longest opening time $t_{i}$ has the shortest $t_{s}$ time (Fig. 2). This causes the limited short-circuit current $I_{\text {cut off }}$ to be the smallest. The breaker has a compact design of main and arcing contacts, short arcing cones and arc chute solutions allow for quick extension and extinguishing of the arc.

The parameters described in this section have a significant impact on the coordination of short-circuit protection in the vehicle-substation system. In order to ensure the highest level of coordination, the rolling stock breaker should limit the short-circuit current to the lowest level in the shortest possible time [11]. This means that in addition to the opening time, also the contact arc time should have possible small values. The higher the shortcircuit current steepness, the higher the $t_{i}$ and $t_{s}$ time requirements are set for the rolling stock breakers.

Selecting circuit breakers only taking into consideration their opening time does not guarantee the coordination of protection. In the case of long $t_{s}$ times, short-circuit current will rise to the value at which the breaker in the traction substation is tripped. 


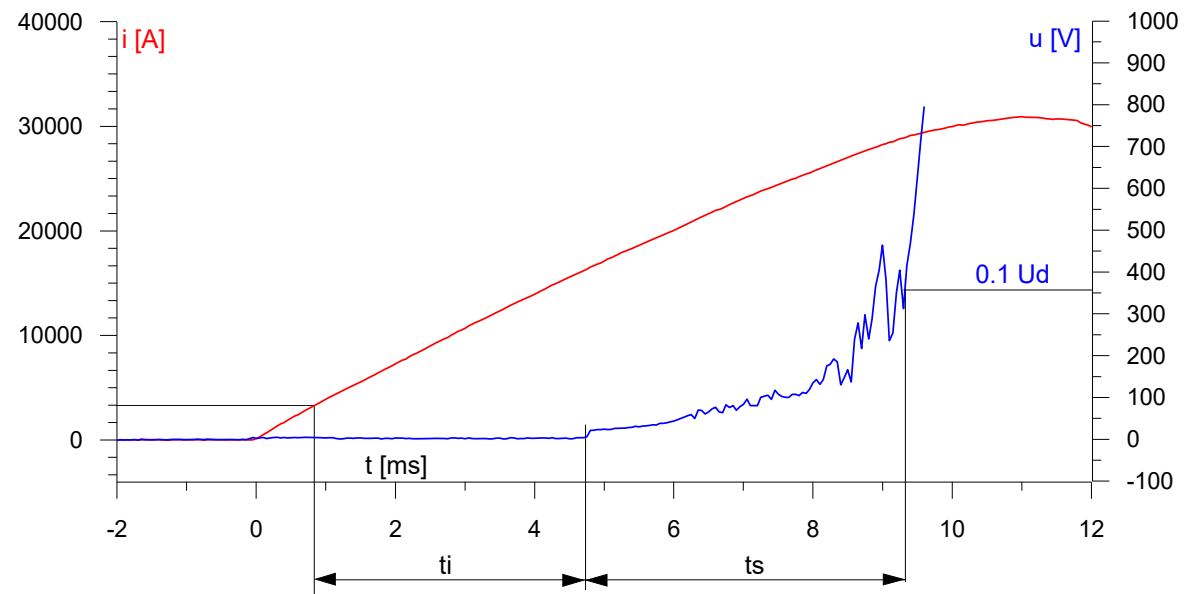

Fig. 2. Short-circuit current flows, voltage at HSCB type $1: t_{i}=3.9 \mathrm{~ms} ; t_{s}=3.6 \mathrm{~ms} ; I_{\text {cut off }}=30.9 \mathrm{kA}, t_{b}=23 \mathrm{~ms}$.

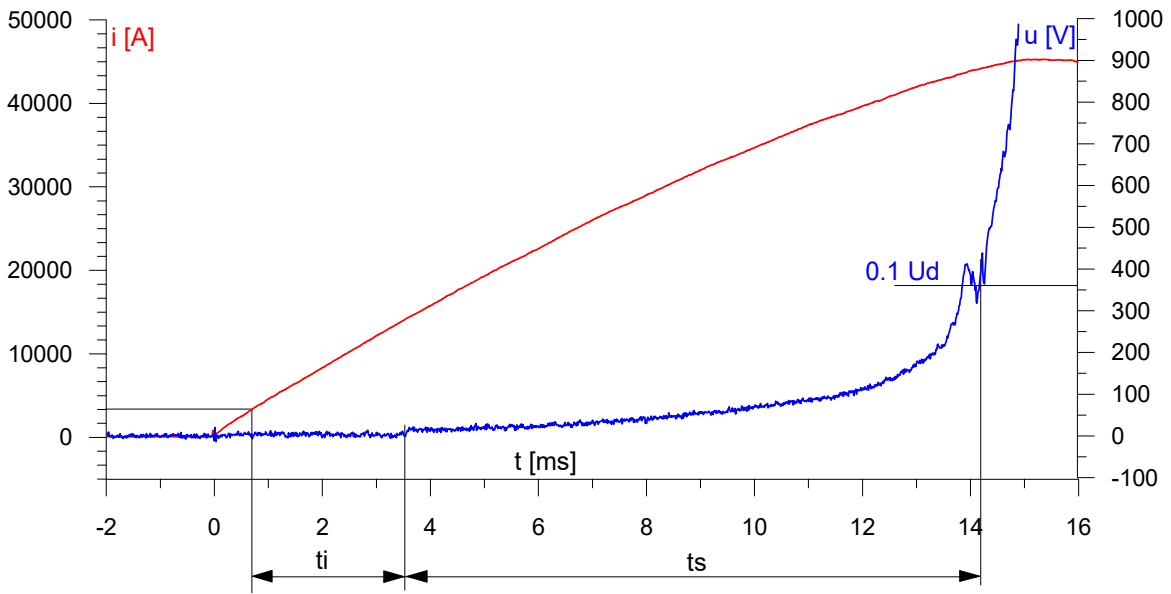

Fig. 3. Short-circuit current flows, voltage at HSCB type $2: t_{i}=2.8 \mathrm{~ms} ; t_{s}=10.6 \mathrm{~ms} ; I_{\text {cut off }}=45.3 \mathrm{kA}, t_{b}=39 \mathrm{~ms}$.

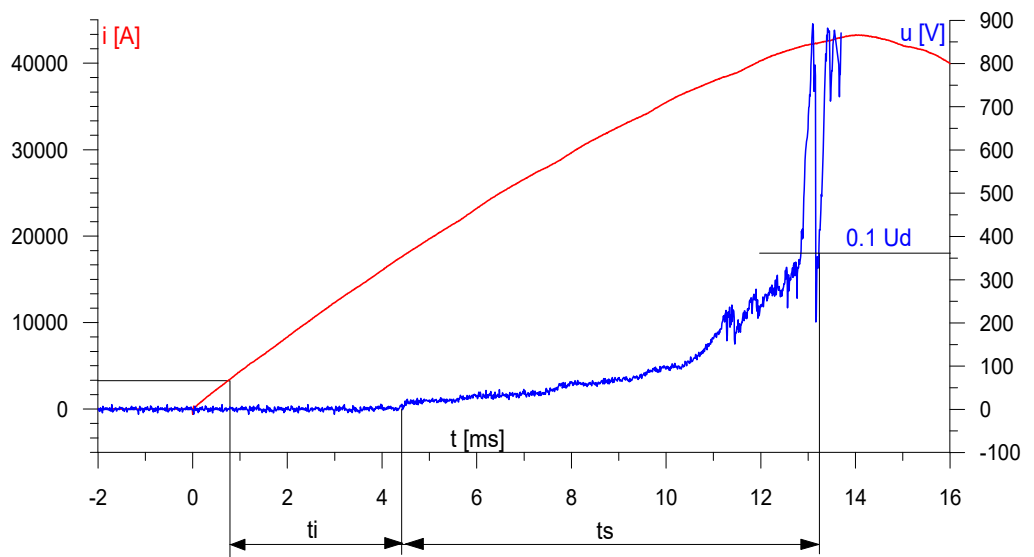

Fig. 4. Short-circuit current flows, voltage at HSCB type $3: t_{i}=3.6 \mathrm{~ms} ; t_{s}=8.8 \mathrm{~ms} ; I_{\text {cut off }}=43.2 \mathrm{kA}, t_{b}=26 \mathrm{~ms}$.

\subsection{The influence of the breaking current and circuit parameters on contact arc time}

The tests were carried out on a system powered by a 6pulse rectifier set. The values of resistance and inductance in the circuit were selected so that in each test a similar value of the time constant of the circuit would be obtained. This means that with the rise in the expected sustained short-circuit current $I_{S S}$, the steepness of the short-circuit current $\mathrm{d} i / \mathrm{d} t$ rose. The setting of the breaker in all tests was $I_{d}=1500$ A.A HSCB blowout magnet was used for the tests with a rated voltage of 3.6 $\mathrm{kV}$, fitted only with main contacts and a blowout coil.

Three series of tests were carried out: at a constant time $t_{c} \approx 16.4 \mathrm{~ms}(15.4-17.1 \mathrm{~ms}), t_{c} \approx 9.2 \mathrm{~ms}(7.9-$ $10.8 \mathrm{~ms}$ ) and a system without additional glands ( $t_{c}$ from 0.8 to $3.1 \mathrm{~ms}$ ). On the basis of recorded voltage flows on the circuit-breaker and short-circuit current, for each test the contact arc time $t_{s}$ and the arcing time $t_{a}$ were 
determined. On the basis of the obtained results, correlations were determined:

- $t_{s}=\mathrm{f}(\mathrm{d} i / \mathrm{d} t)$;

- $t s / t a=f(d i / d t)$;

- $t s=f(t c)$;

- $t s / t a=f(t c)$;

- $t s=f($ Icut off $)$;

- $t s / t a=f($ Icut off).

The flows of the aforementioned correlations are presented in Figures 5 - 10. The results of measurements marked with points were approximated by a linear function. Examples of voltage flows on the breaker and the switched off current are shown in Figures $11-14$.

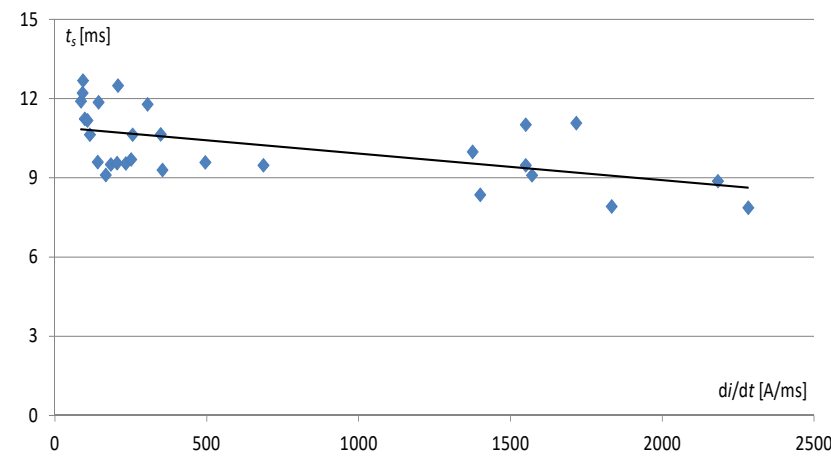

Fig. 5. Contact arc time $t_{s}$ correlation with the speed of the current rise $\mathrm{d} i / \mathrm{d} t$.

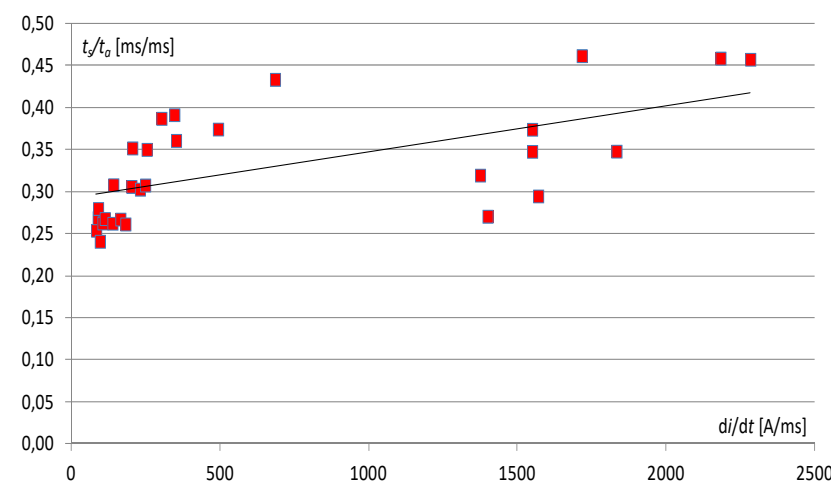

Fig. 6. Contact arc time $t_{s}$ and arcing time $t_{a}$ correlation with the speed of the current rise $\mathrm{d} i / \mathrm{d} t$.

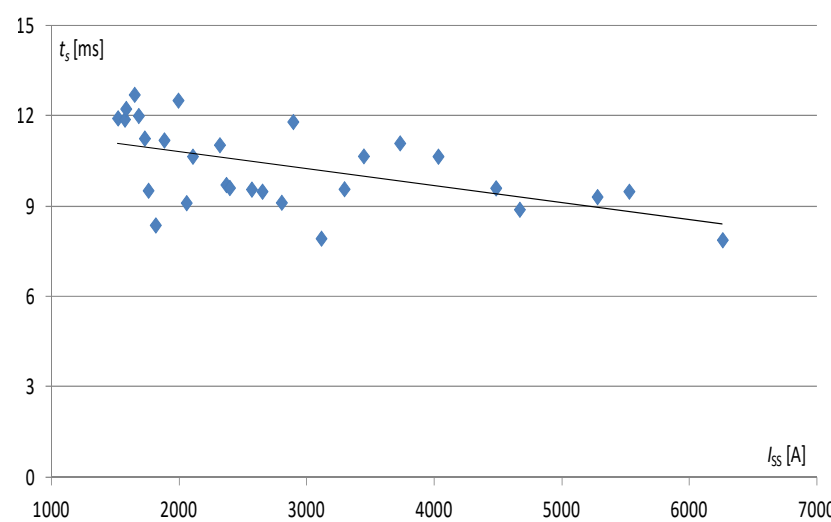

Fig. 7. Contact arc time $t_{s}$ correlation with the prospective sustained short-circuit current $I_{\mathrm{SS}}$.

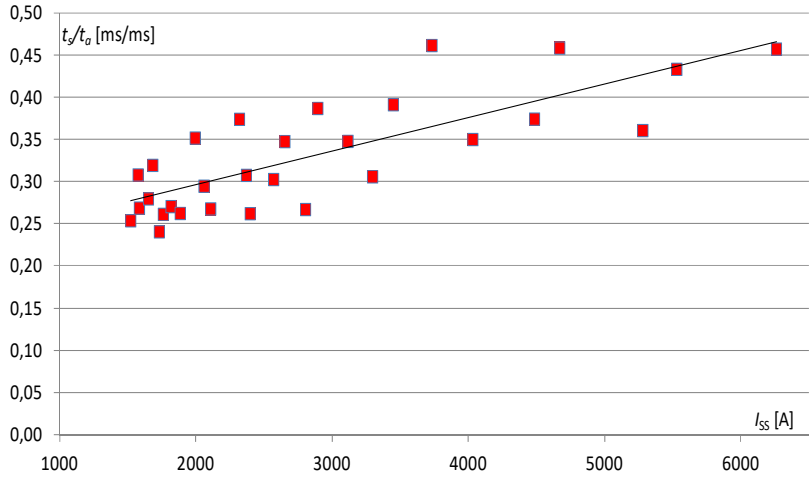

Fig. 8. Contact arc time $t_{s}$ and arcing time $t_{a}$ correlation with the prospective sustained short-circuit current $I_{\mathrm{SS}}$.

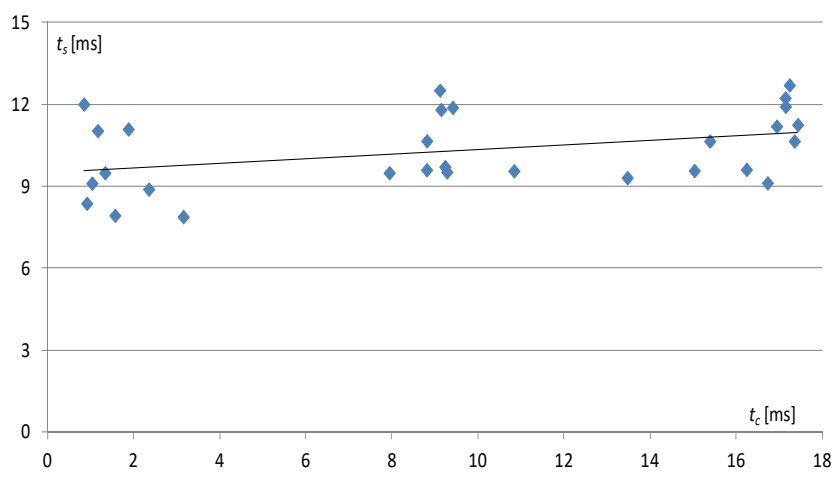

Fig. 9. Contact arc time $t_{s}$ correlation with the circuit time constant $t_{c}$.

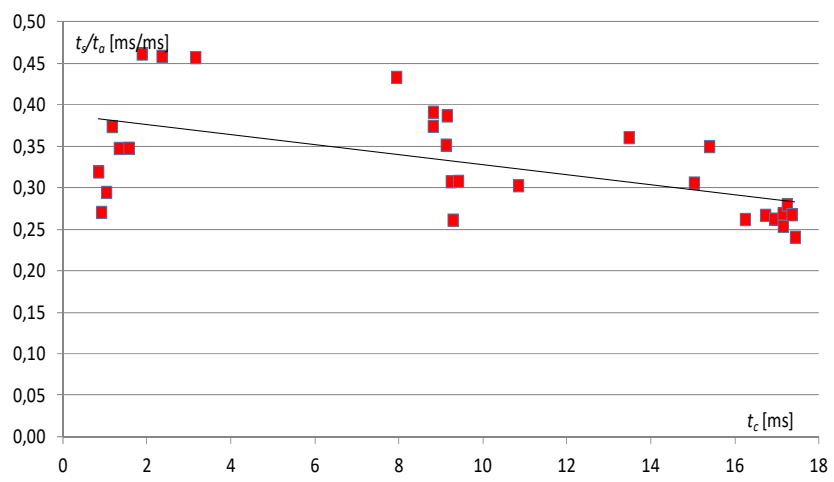

Fig. 10. Contact arc time $t_{s}$ and arcing time $t_{a}$ correlation with the circuit time constant $t_{c}$.

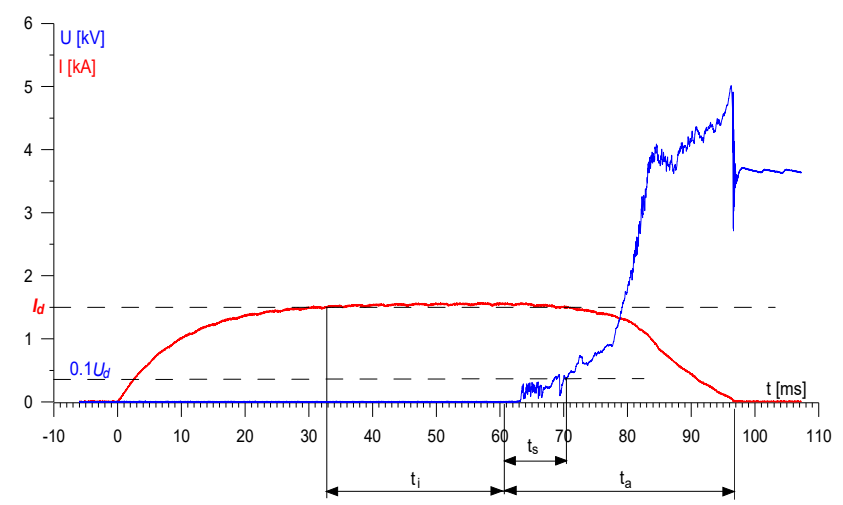

Fig. 11. The voltage flow on breaker's contacts and switch-off current at: $\mathrm{d} i / \mathrm{d} t=143 \mathrm{~A} / \mathrm{ms}, t_{c}=9.4 \mathrm{~ms}$ [13]. 


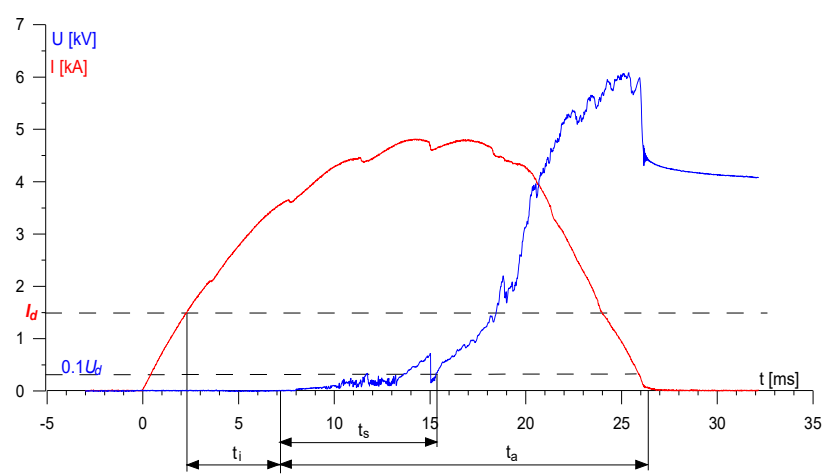

Fig. 12. The voltage flow on breaker's contacts and switch-off current at: $\mathrm{d} i / \mathrm{d} t=353 \mathrm{~A} / \mathrm{ms}, t_{c}=13.5 \mathrm{~ms}$ [13].

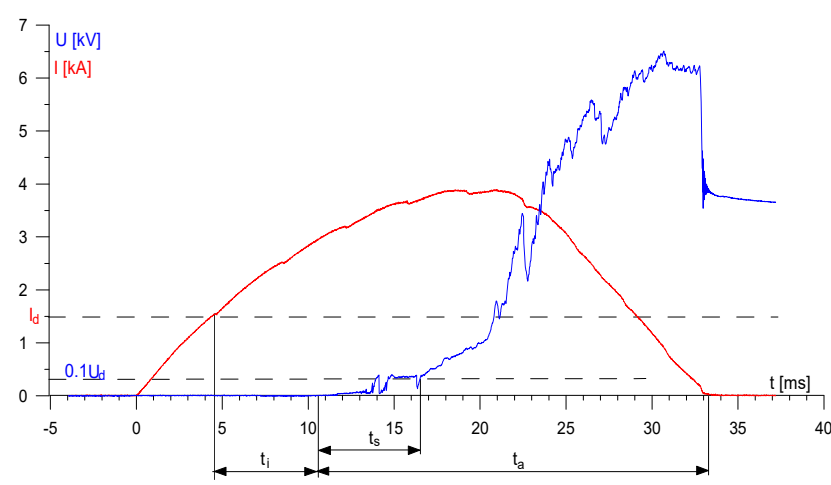

Fig. 13. The voltage flow on breaker's contacts and switch-off current at: $\mathrm{d} i / \mathrm{d} t=686 \mathrm{~A} / \mathrm{ms}, t_{c}=7.9 \mathrm{~ms}[13]$.

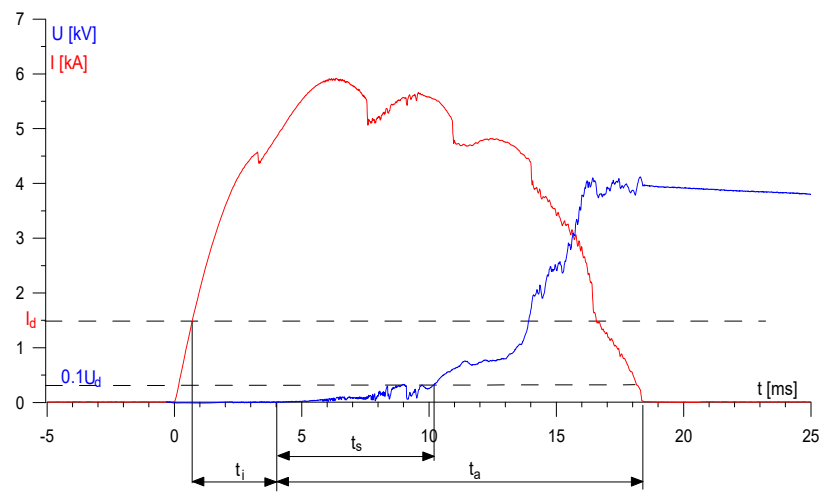

Fig. 14. The voltage flow on breaker's contacts and switch-off current at: $\mathrm{d} i / \mathrm{d} t=2283 \mathrm{~A} / \mathrm{ms}, t_{c}=3.2 \mathrm{~ms}$ [13].

On the basis of Figures 5, 7 and 9 it can be concluded that the contact arc time $t_{s}$ of the tested circuit breaker depends only slightly on the parameters of the short circuit and the current. The rise in the time constant of the $t_{c}$ circuit causes the rise of the $t_{s}$. It is estimated that the $t_{c}$ rise by $1 \mathrm{~ms}$ causes the $t_{s}$ rise by approximately $0.08 \mathrm{~ms}$. However, the increase in the $\mathrm{d} i / \mathrm{d} t$ current steepness and the value of the expected short-circuit current $I_{\mathrm{SS}}$ result in a small decrease in the contact arc time $t_{s}$. By approximating the measurement data with the linear function, the decrease can be estimated in the contact arc time $t_{s}$ by about $1.1 \mathrm{~ms}$ with the increase in $\mathrm{d} i / \mathrm{d} t$ by $1 \mathrm{kA} / \mathrm{ms}$ and by about $0.5 \mathrm{~ms}$ with the increase of the $I_{\mathrm{SS}}$ by $1 \mathrm{kA}$.

The parameters of the circuit and short-circuit current affect the arcing time $t_{a}$, which value rises with the increase of the time constant of the $t_{c}$ circuit and drops with the increase of $\mathrm{d} i / \mathrm{d} t$ and $I_{\mathrm{SS}}[13,14]$. The influence of these parameters on the arcing time value is much stronger than on the contact arc time $t_{s}$. Therefore, the $t_{s} / t_{a}$ diagrams in the $\mathrm{d} i / \mathrm{d} t$ function (Fig. 6), $I_{\mathrm{SS}}$ (Fig. 8) and $t_{c}$ (Fig. 10) are inverse in character than those shown in Figures 5, 7 and 9.

Analyzing the measurement results, the value of the current assumed as the end of the contact arc time was also determined, thus when the arc voltage $u_{a}$ reaches 0.1 $U_{d}$ (See: Fig. 1). In a series of measurements at arcing time $t_{c} \approx 16.4 \mathrm{~ms}$ at $u_{a}=0.1 U_{d}$ had a value less than the maximum current of $0.6 \%$ to $3 \%$ (on average $1.5 \%$ ). In the case of the time constant $t_{c} \approx 9.2 \mathrm{~ms}$ the short-circuit current was lower by $0.3 \%$ to $3.3 \%$ (on average $1.4 \%$ ).

The afore mentioned analysis for series of measurements for small values of time constant was not possible. This resulted from the character of short-circuit current flows (See: Fig.14). Due to strong current pulsations, the change in its value within $1 \mathrm{~ms}$ can reach almost $1.2 \mathrm{kA}$. This means that in case of $t_{s}$ shorter or longer by $1 \mathrm{~ms}$, a significant difference in the shortcircuit current momentary value can occur.

\subsection{The influence of the number of breakings on contact arc time}

The aim of subsequent tests was to determine if the number of breakings performed by the high-speed circuit breaker has an effect on the contact arc time of this circuit breaker. These tests were carried out using a new high-speed circuit breaker. 300 breakings of the operating current of approximately 1400 A were carried out in a circuit with a time constant tc $=15 \mathrm{~ms}$. During the tests, no service and maintenance of the breaker were carried out. Examples of the switched off current and voltage flows at the circuit breaker terminals are presented in Figures 15 and 16.

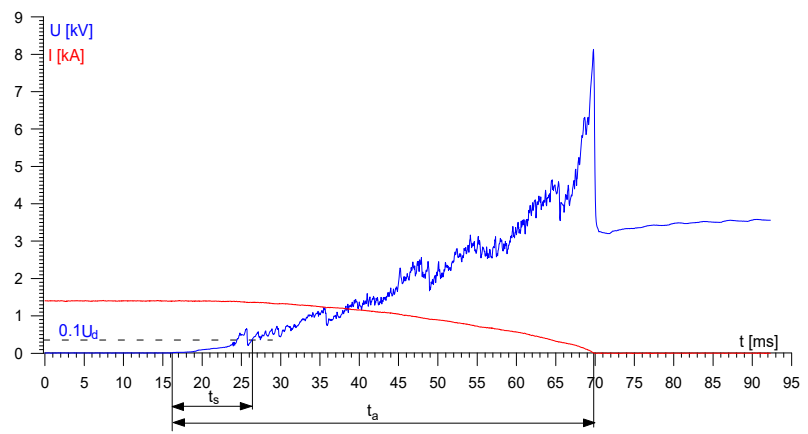

Fig. 15. The voltage flow on breaker's contacts and switch-off current -1 . breaking: $t_{s}=10.05 \mathrm{~ms}, t_{a}=53.50 \mathrm{~ms}$.

Figure 17 shows the changes of the arcing time $t_{a}$ depending on the number of breakings $n$, whereas Fig. 18 presents the effect of the number of breakings $n$ on the length of contact arc time $t_{s}$. Results of tests of every 20 breakings are shown in both pictures. According to predictions, the arcing time $t_{a}$ increased together with the rise of breakings $n$. This is due to the degradation of contacts and arcing chute, which together with the growth of the wear rate has a smaller potential for extinguishing the arc. 


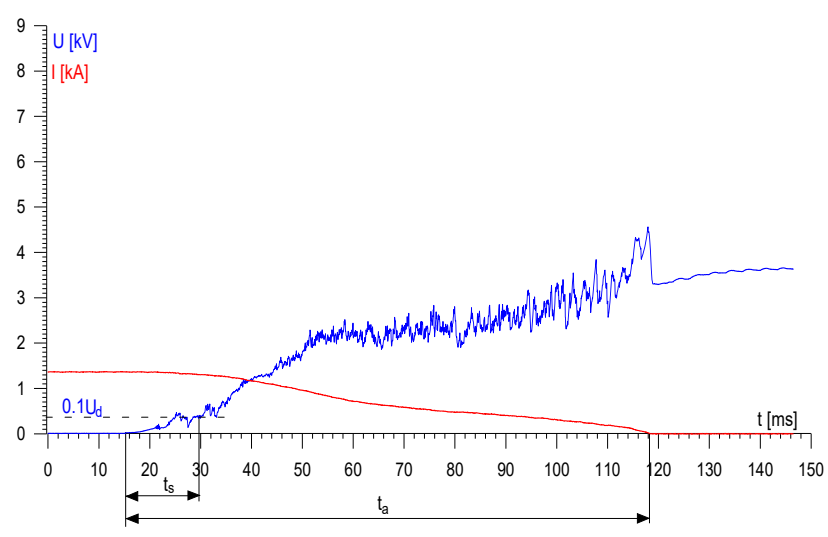

Fig. 16. The voltage flow on breaker's contacts and switch-off current -300 . breaking: $t_{s}=14.30 \mathrm{~ms}, t_{a}=102.85 \mathrm{~ms}$.

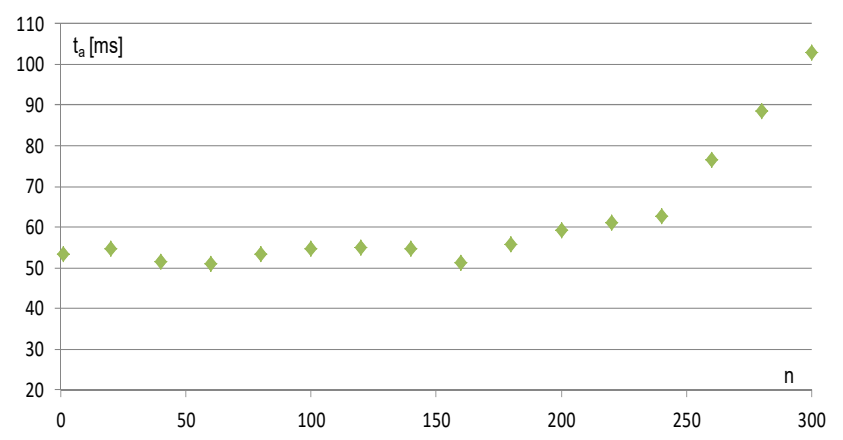

Fig. 17. Contact time $t_{a}$ correlation with the number of breakings $n$.

Analyzing the measurement results in terms of contact arc time $t_{s}$, its rise was also noticed (Fig. 18) together with the growth of the number of breakings $n$. Comparing the contact arc time during the first and $300^{\text {th }}$ breaking, $t_{s}$ increased from $10.05 \mathrm{~ms}$ to $14.30 \mathrm{~ms}$, i.e. by about $42 \%$, whereas the arcing time increased by about $92 \%$. Approximating the measurement results of contact arcing time with the linear function, it can be estimated that $t_{s}$ increases by about $1.4 \mathrm{~ms}$ for every 100 breakings. That means that together with the rise of the number of breakings $n$, the contact arc time $t_{s}$ has a smaller share in the arcing time $t_{a}$.

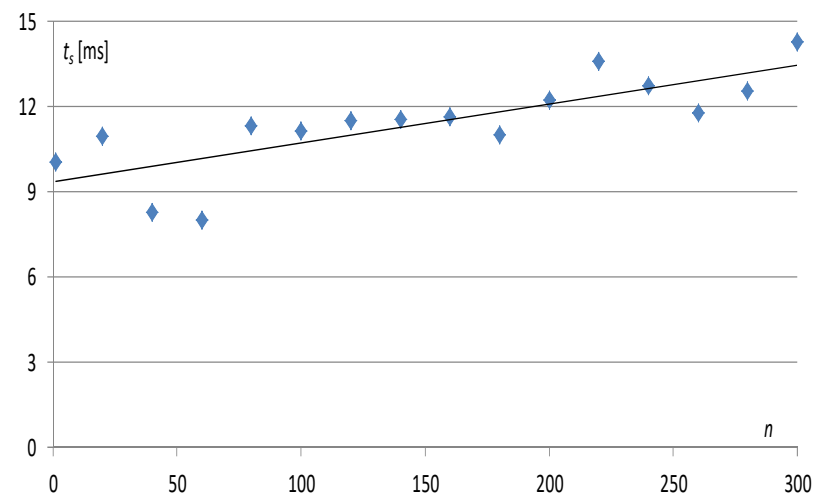

Fig. 18. Contact arc time $t_{s}$ correlation with the number of breakings $n$.

The above correlations change when frequent highspeed breaker's service and maintenance activities are conducted.
Analyzing the results of the research on the influence of the number of breakings on the value of time ts, the value of the current at the time considered as the end of the contact arc time was also determined. In this series of measurements at short-circuit current at $u_{a}=0.1 U_{d}$ had a value lower than the maximum current by $0.3 \%$ to $4.3 \%$, with the average short-circuit current limitation was $2.0 \%$ for the first 100 breakings, $2.7 \%$ for breakings from $n=101$ to $n=200$ and $3.3 \%$ for breakings from $n=$ 201 to $n=300$

\section{Summing up and conclusions}

The article discusses the issue of time when the contact arc appears while DC breaking by a high-speed circuit breaker. This parameter is not defined in standards that deal with high-speed circuit breakers and their tests. This parameter is extremely important, among others, to achieve proper coordination of short-circuit protection in the traction substation-traction vehicle system. For this reason, a proposal is presented for the definition of contact arc time which is defined as the time from HSCB contacts opening until the arc reaches the voltage of 0.1 supply voltage. Using this definition, tests of this time and its correlation with other variables were carried out.

The test results presented in his article that the contact arc time $t_{s}$ is a significant part of the arcing time $t_{a}$. The length of the arcing time $t_{a}$ is influenced by many factors, including short-circuit parameters, switched off current and the breaker's construction.

The contact arc time $t_{s}$ depends on the high-speed breaker's construction. This time can constitute even $33 \%$ of the total break time $t_{b}$ and is longer than the breaker's opening time $t_{i}$. When the contact arc time $t_{s}$ appears, the short circuit current is practically unlimited. For circuits of time constant $t_{c}$ of over $7 \mathrm{~ms}$ the current limitation during contact arc does not exceed $4 \%$ of the current maximum value. For this reason the contact arc time strongly affects the potential of short-circuit current's limitation and the break time.

The contact arc time $t_{s}$ depends in a very small degree on the time constant $t_{c}$, the speed of the current rise $\mathrm{d} i / \mathrm{d} t$ and expected value of short-circuit current $I_{\mathrm{SS}}$ switched off by a high-speed breaker. Basing on the conducted research it has been estimated that the rise of circuit time constant $t_{c}$ of $1 \mathrm{~ms}$ causes the extension of the contact arc time $t_{s}$ by the time measured in a fraction of a millisecond for every $1 \mathrm{kA} / \mathrm{ms}$ or $1 \mathrm{kA}$.

The HSCB technical condition affects the contact arc time $t_{s}$, however, it is much smaller than the influence on the arcing time $t_{a}$. The test results showed that performing 300 breakings of operating current caused the rise of $t_{s}$ time in the degree more than half of the arcing time $t_{a}$.

Therefore it can be concluded that in order to significantly shorten the contact arc time $t_{s}$, it is necessary to analyze the HSCB construction as well as elements responsible for the emergence of the arc in the arc chute. 


\section{References}

1. Bartosik, M., Lasota, R., Wójcik,, F.: New generation of ultra-high-speed current-limiting circuit - breakers for electric traction of direct current. TTS Technika Transportu Szynowego no. 7-8, 80 - 88 (2000).

2. Bartosik,M., Lasota, R., Wójcik, F.: High speed circuits breakers type DCN for substation. TTS Technika Transportu Szynowego no. 10, 55 - 59 (2003).

3. EN 50123-1:2003. Railway applications. Fixed installations. D.C. switchgear. Part 1: General.

4. EN 50123-2:2003. Railway applications. Fixed installations. D.C. switchgear. Part 2: D.C. circuit breakers.

5. EN 60077-1:2002. Railway applications - Electric equipment for rolling stock. Part 1: General service condition and general rules.

6. EN 60077-2:2002. Railway applications - Electric equipment for rolling stock. Part 2: Electrotechnical components - General rules.

7. EN 60077-3:2002. Railway applications - Electric equipment for rolling stock. Part 3: Electrotechnical components - Rules for d.c. circuit-breakers.

8. Maciołek, T., Mierzejewski, L., Szeląg, A.: Breaking the short-circuits in DC traction by high-speed circuits breakers and power-switch. TTS Technika Transportu Szynowego no. 3, 40 - 47 (2001).

9. Mierzejewski, L., Szeląg, A.: Research of short circuits and overvoltages in DC electric traction circuits with single-stage transformations $110 / 3 \mathrm{kV} .4^{\text {th }}$ International Conference MET'99, pp. 58 - 60, Warsaw (1999).

10. Rojek, A., Sidorowicz, M.: Research and tests of highspeed circuit breakers for rolling stock and substations in $3 \mathrm{kV}$ DC traction power system. Railway Reports 159, 7 $26(2013)$

11. Rojek, A., Zbieć, A.: Co-ordination of Short Circuit Protection Devices in Motive Power Unit - Sub-station System. Railway Reports 159, 27 - 46 (2012).

12. Rojek, A.: Parameters of DC high-speed circuit-breakers. MATEC Web of Conferences 180, 06006 (2018).

13. Rojek, A.: Switching-off time of electromagnetic blow-out high-speed DC circuit breaker. Railway Reports 169, 53 60 (2015)

14. Wójcik, F.: Theoretical analysis of possibilities for improvement in the effective operation of DC magnetic blow-out circuit breakers. Electrical Review R. 87 no. 5/2011, 186 - 192 (2011).

15. Sechéron Homepage, www.secheron.com, last accessed 2019/03/18 